\title{
O DIREITO FUNDAMENTAL DO TELETRABALHADOR AO MEIO AMBIENTE DE TRABALHO SADIO ${ }^{1}$
}

\author{
THE REMOTE WORKER'S FUNDAMENTAL RIGHT TO A HEALTHY \\ WORKING ENVIRONMENT
}

Theanna de Alencar Borges ${ }^{2}$

\begin{abstract}
Resumo: A pandemia do novo coronavírus (COVID-19) alçou o teletrabalho, instituto até então pouco utilizado na prática empresarial brasileira, a instrumento central na busca pela preservação dos postos de trabalho e de manutenção das empresas. O objetivo do estudo é analisar se o teletrabalhador, que por meio das tecnologias da informação e comunicação pode realizar seu trabalho em qualquer lugar, possui direito fundamental a um ambiente de trabalho equilibrado. A pesquisa é do tipo bibliográfica, com fins descritivo e exploratório, mediante análise da legislação nacional e, ainda, do Direito Internacional do Trabalho aplicável. Conclui-se que, a despeito da escassa regulamentação do teletrabalho no Brasil, o teletrabalhador possui direito fundamental a um ambiente laboral sadio, mesmo que o trabalho seja desempenhado a distância. Deve o empregador promover a saúde e segurança física, mental e emocional do teletrabalhador, concretizando as normas da Constituição da República Federativa do Brasil de 1988 e do ordenamento jurídico brasileiro sobre o meio ambiente de trabalho, atuando prioritariamente de forma preventiva e precavida.
\end{abstract}

Palavras-chave: Teletrabalho; Home office; Tecnologias da informação e comunicação - TIC; Direito fundamental; Meio ambiente de trabalho.

\begin{abstract}
The new coronavírus' pandemic (COVID-19) has made remote work, an institute that until then was hardly ever used in Brazilian business practice, as the central instrument aiming the preservation of jobs and the maintenance of companies. The main goal of the study is to analyze if the remote worker, who through information and communications technology can perform his work anywhere, has a fundamental right to a balanced working environment. The research is bibliographic type, with descriptive and exploratory purposes, through analysis of the national legislation and, also, the applicable International Labor Law. It is concluded that, despite the scarce regulation of telework in Brazil, teleworkers have a fundamental right to a healthy working environment, even if the work is performed at a distance. The employer must promote their physical, mental and emotional health and safety, following the norms of the Constitution of the Federative Republic of Brazil of 1988 and the Brazilian legal system on the work environment, acting primarily in a preventive and precautionary way.
\end{abstract}

\footnotetext{
1 Artigo apresentado ao I Congresso Internacional do Instituto Universitário do Rio de Janeiro - Direito Contemporâneo: Perspectivas e Desafios, realizado nos dias 30 e 31 de Julho de 2020, com transmissão no link: https://www.youtube.com/watch?v=3XqX-RgJKGY\&t=19511s, a partir das 07:03:40.

2 Mestranda em Ciências Jurídicas pela Universidade Autónoma de Lisboa "Luís de Camões" - UAL (Lisboa, Portugal). Especialista em "Derechos Humanos Laborales y Gobernanza Global" pela Universidade de CastillaLa Mancha - UCLM (Toledo, Espanha, 2019). Especialista em Direito do Trabalho pela Universidade Cândido Mendes (Rio de Janeiro, Brasil, 2010). Pesquisadora voluntária do Grupo de Estudos Em Direito e Assuntos Internacionais da Universidade Federal do Ceará - GEDAI UFC (Fortaleza, Ceará, Brasil) e do Projeto Direito Internacional Sem Fronteiras - DISF (Juiz de Fora, Minas Gerais, Brasil). Juíza do Trabalho Substituta do Tribunal Regional do Trabalho da 16a Região (Imperatriz, Maranhão, Brasil). ORCID: https://orcid.org/0000-0002-1628527X. Currículo Lattes: http://lattes.cnpq.br/6293026504154551. E-.mail: theannaborges@ hotmail.com.
} 
Keywords: Remote work; Working from home; Information and communications technology - ITC; Fundamental right; Working environment.

\section{Introdução}

A pandemia do novo coronavírus transformou o teletrabalho em um dos maiores protagonistas na tentativa de equilibrar a exigência de isolamento social para evitar o contágio e impedir a propagação da doença com a necessidade de manter as empresas em funcionamento e, ainda, preservar os postos de trabalho, impedindo o total colapso da economia.

Desta forma, o teletrabalho, figura ainda até então pouco utilizada na prática empresarial brasileira, transmutou-se em figura essencial para o Direito do Trabalho no cenário pandêmico, sendo muito provável que, no período pós-pandemia, continuará sendo relevante não apenas no Brasil, mas em todo o mundo.

É fato que as empresas não tiveram muito tempo para se preparar para o teletrabalho e isso pode acarretar sérias consequências para a saúde, a higiene e a segurança do trabalhador, notadamente em virtude dos riscos ergonômicos e psicossociais a que os teletrabalhadores estão expostos. Por corolário, poderá trazer consequências nefastas para as empresas que não promoverem as adequações necessárias.

O objetivo deste estudo é contribuir para o debate acerca do meio ambiente laboral sadio para o teletrabalhador, especialmente em se considerando o atual estágio da legislação brasileira sobre o assunto. Para tanto, foi feita pesquisa do tipo bibliográfica, com fins descritivos e exploratórios, mediante análise da legislação nacional e, ainda, do Direito Internacional do Trabalho aplicável.

Inicialmente, a pesquisa estabelece o conceito de teletrabalho e faz distinções entre ele e outras figuras correlatas. Em seguida, analisa como a regulamentação do meio ambiente de trabalho do teletrabalhador ocorre no Brasil. Por fim, analisa como pode ocorrer a concretização do direito fundamental ao meio ambiente de trabalho sadio do teletrabalhador.

\section{Considerações iniciais sobre o teletrabalho e outras distinções}

A Consolidação das Leis do Trabalho - CLT foi alterada, para incluir os artigos 75-A a 75-E pela Lei no 13.467/2017 (mais conhecida como "reforma trabalhista"), para regulamentar a figura do teletrabalho. A referida alteração, inspirada no Código do Trabalho Português, regulamentou o teletrabalho brasileiro, cujo labor ocorre por meio das tecnologias da 
informação e comunicação - TICs, preponderantemente fora da empresa, distinguindo-se do trabalho externo e também do em domicílio (CASSAR, 2018; DELGADO; DELGADO, 2017).

Percebe-se, portanto, que, de acordo com a CLT reformada, o comparecimento eventual à empresa não afasta o regime de teletrabalho. A expressão comparecimento eventual compreende conceito jurídico indeterminado que será interpretado caso a caso, a depender da prova que vier a ser produzida. Desta forma, o comparecimento eventual para reuniões, treinamentos ou assinatura física de documentos, por exemplo, não invalida o regime de teletrabalho.

Entretanto, configurada a não eventualidade do comparecimento ao estabelecimento empresarial, desvirtuado estará o regime do teletrabalho, por força do art. $9^{\circ}$ da CLT. Concordase, assim, com Delgado; Delgado (2017, p. 138):

Naturalmente que, sendo excessivos ou preponderantes esses comparecimentos ao estabelecimento empresarial, pode se descaracterizar o regime de teletrabalho, em vista de se tornar plenamente factível o controle de jornada pelo empregador. Contudo, trata-se de matéria eminentemente fáticoprobatória, em que tende a vigorar o império do caso concreto posto à análise.

Importante ressaltar que o art. $6^{\circ}$ da CLT já havia sido alterado em 2011 para estabelecer a equiparação no que diz respeito aos meios presenciais e telemáticos de subordinação, consagrando a "teoria da subordinação estrutural", nos dizeres de Delgado; Delgado (2017, p. 137), o que já autorizava o uso do teletrabalho.

Ocorre que o referido artigo ainda gerava diversas discussões quanto ao tema, razão pela qual é possível considerar que houve avanço com a reforma trabalhista nesse tocante, tendo em vista que pacificou a questão quanto à existência de subordinação jurídica no teletrabalho nas relações empregatícias (DELGADO; DELGADO, 2017). A despeito disso, novos debates surgiram no que se refere a outros aspectos, como, por exemplo, quanto à duração do trabalho, à responsabilidade pelos instrumentos de trabalho e ao meio ambiente de trabalho.

Quanto às distinções entre o teletrabalho e outros institutos, destaque-se que o trabalho externo também não se confunde com o teletrabalho, uma vez que o trabalho externo é aquele cuja prestação de trabalho necessariamente precisa ocorrer fora das dependências da empresa, por sua própria essência, podendo também eventualmente haver o comparecimento à empresa, sem que isso descaracterize o trabalho externo. É possível que haja o uso de TICs para a prestação de trabalho externo, entretanto o uso das mencionadas tecnologias não é inerente a essa modalidade contratual.

A terminologia utilizada na legislação brasileira não tem sido popularmente utilizada, tanto que na pandemia do novo coronavírus, o léxico "home office" passou a ser empregado 
majoritariamente pela população e pela imprensa. Ocorre que o Direito do Trabalho brasileiro optou por usar a expressão trabalho a distância como gênero, de que o teletrabalho é espécie. Tecnicamente, o "home office" é aquele prestado no domicílio do trabalhador, que pode ou não se valer das TICs para desempenhar seu trabalho. Ademais, registre-se que a CLT, em seu texto original, já previa o trabalho em domicílio no seu art. 83, que tipicamente era usado para atividades manuais, a exemplo de serviço de costura.

Consoante Cassar (2018, p. 669), seriam sinônimos do teletrabalho as expressões "trabalho remoto", "trabalho periférico" e "trabalho a distância". Em que pese o respeito à referida opinião, discorda-se desta última nomenclatura, porquanto o teletrabalho se enquadra como espécie de trabalho a distância, não se confundindo com ele.

Desta forma, percebe-se que, no Brasil, não importa o local em que o trabalhador presta o serviço, podendo fazê-lo no local de sua livre escolha por decisão do empregador quanto à modalidade de teletrabalho. Tal modalidade é típica da sociedade da informação (AMADO, 2019), em que as TICs revolucionaram o modo de vida dos indivíduos, das empresas, da sociedade como um todo e do Estado.

Dentre as principais as vantagens do teletrabalho, merecem ser salientadas principalmente a flexibilidade de horário de trabalho e maior liberdade para organização de atividades pessoais. No entanto, há inúmeras desvantagens de caráter físico e também psicossocial, acrescidas à dificuldade de gestão do que é trabalho e do que é vida pessoal e familiar, o que demanda a preocupação com a saúde, a higiene e a segurança do teletrabalhador. Nesse sentido, Amado (2019, p. 130):

[...] É claro que a estas vantagens (reais ou virtuais) há que contrapor os inegáveis inconvenientes do teletrabalho, sobretudo do teletrabalho domicilário: maior isolamento do trabalhador, com o inerente risco de desenraizamento social, desgaste psicológico, falta de solidariedade e empobrecimento da dimensão coletiva do trabalho; alguma diluição das fronteiras entre a vida profissional e extraprofissional, o que pode ameaçar a reserva da vida privada do trabalhador ou aumentar a conflitualidade familiar, bem como provocar a ultrapassagem dos limites legais em matéria de tempo de trabalho, etc.

Dir-se-ia, em suma, que com o teletrabalho a situação típica inverte-se, sendo o trabalho que, de algum modo, se desloca até ao trabalhador. E as novas tecnologias permitem, justamente, vencer a distância [...].

Feitas essas distinções iniciais, faz-se necessário compreender o ordenamento juslaboral brasileiro no que diz respeito à opção legislativa da Lei n $13.467 / 2017$ quanto à temática do meio ambiente laboral do teletrabalhador. 
A regulamentação do meio ambiente de trabalho do teletrabalhador pela Lei $\mathbf{n}^{\circ}$ 13.67/2017

As questões relativas à proteção e à saúde do trabalhador remontam às origens do Direito do Trabalho, cujas primeiras legislações eram reflexos das lutas dos trabalhadores, para além de pretensões por melhores salários, por condições de trabalho mais seguras e adequadas.

Especificamente no Brasil, com o advento da figura do teletrabalho, esperava-se que houvesse uma regulamentação própria da questão do meio ambiente de trabalho do teletrabalhador, considerando-se as especificidades da situação, que se diferencia do trabalho em domicílio em virtude de ele poder se realizado em qualquer lugar, a critério do teletrabalhador.

Entretanto, não foi isso que ocorreu, já que a CLT foi lacônica quanto ao meio ambiente de trabalho do teletrabalhador (art. 75-E), limitando-se a estabelecer que o empregador deve instruir os empregados, expressa e ostensivamente, sobre precauções para evitar doenças e acidentes de trabalho, sendo dever do empregado assinar termo de responsabilidade de que cumprirá mencionadas instruções.

A CLT reformada adotou a teoria do ato inseguro, criticada no direito brasileiro, havendo sido substituída, a partir da alteração da Norma Regulamentadora - NR $\mathrm{n}^{\mathrm{o}} 1$, pela teoria da condição insegura, que sustenta que o acidente laboral é decorrência de múltiplos elementos característicos da condição insegura de trabalho a que o trabalhador foi exposto.

Assim, a opção do legislador reformista merece severas críticas, uma vez que o teletrabalhador está sujeito a riscos que se diferem do trabalhador presencial, especialmente em se considerando a ergonomia do trabalho, o isolamento social provocado pelo distanciamento dos colegas de trabalho, a extensão do horário de trabalho e a dificuldade de desconexão, o que pode conduzir ao agravamento dos riscos ergonômicos e à saúde mental.

De qualquer sorte, Silva (2019, p. 59-60) ressalta um aspecto positivo quanto ao art. 75E da CLT:

14. O capítulo do teletrabalho [...] tem a virtude de admitir que acidentes de trabalho podem ocorrer, portanto, dentro da casa do empregado e não exclusivamente dento das dependências do empregador. Mas, como visto acima, haverá muita discussão pela frente. [...]

Quanto à temática da ampliação do meio ambiente de trabalho para ambientes privados em razão do teletrabalho, notadamente quanto aos riscos de doenças e acidentes do trabalho, convém transcrever o ensinamento de Delgado; Delgado (2017, p. 139-140): 
Pela lógica do teletrabalho, que estende, em alguma medida, o conceito de meio ambiente do trabalho também para o ambiente privado do trabalhador, pode-se falar, em tese, abstratamente, na possibilidade de responsabilidade empresarial pelos danos da infortunística do trabalho também nesses casos. Porém, não há dúvida de que, concretamente, embora não seja tão árdua a comprovação da configuração do dano, torna-se mais difícil do que o padrão usual a comprovação tanto do nexo causal como, especialmente, da culpa do empregador. Esse é um tema, contudo, que apenas o acúmulo de experiências práticas, ao longo do tempo, poderá agregar maiores dados para a mais aprofundada reflexão a respeito.

Ressalte-se, por oportuno, que no contexto da pandemia da COVID-19, o Presidente da República editou a Medida Provisória n 927/2020, cuja vigência iniciou em 22 de março de 2020 e encerrou em 19 de julho de 2020, que, embora tenha estabelecido disposições sobre o teletrabalho no art. $4^{\circ}$, deixou de mencionar expressamente o meio ambiente de trabalho (SILVA, 2020), tangenciando apenas a questão do direito à desconexão em seu art. $4^{\circ}, \S 5^{\circ}$.

Registre-se, ainda, que o Brasil não ratificou a Convenção no 177 da OIT (que trata do trabalho em domicílio, não especificamente do teletrabalho), entretanto, ratificou a Convenção $\mathrm{n}^{\mathrm{o}} 155$ da OIT (segurança e saúde dos trabalhadores), que trata do objeto deste estudo, possuindo caráter supralegal, sendo, inclusive, passível de controle de convencionalidade, cuja teoria foi desenvolvida por Valerio de Oliveira Mazzuoli ${ }^{3}$.

Em síntese, o controle de convencionalidade consiste na análise da compatibilidade vertical entre a legislação interna com uma norma internacional de direitos humanos ratificada por um Estado, devendo ser feita pelo Judiciário local, inclusive, de ofício (BORGES, 2019). Cabe, portanto, a verificação da legislação do teletrabalho em contraponto com as normas internacionais ratificadas pelo Brasil, dada, no mínimo, a natureza supralegal delas, de acordo com o atual posicionamento do STF (BORGES, 2019).

Pelo exposto, para se compreender se os teletrabalhadores também contam com o direito a um meio ambiente de trabalho equilibrado, ainda que preponderantemente prestem serviço fora da empresa, é forçosa a análise global do ordenamento juslaboral brasileiro.

\section{A concretização do direito fundamental do teletrabalhador ao meio ambiente de}

\section{trabalho sadio}

Em que pese a CLT ter sido lacônica quanto ao meio ambiente de trabalho do teletrabalhador, suas normas não devem ser consideradas isoladamente, uma vez que a

\footnotetext{
3 Para aprofundamento do estudo, v. MAZZUOLI, Valerio de Oliveira. Controle jurisdicional de convencionalidade das leis.
} 
Constituição da República Federativa do Brasil - CRFB/1988 garante o meio ambiente de trabalho equilibrado (arts. 200, VIII, c/c art. 225 da CRFB/1988), direito fundamental de terceira dimensão (BONAVIDES, 2014; MIRANDA, 2018) de todos os trabalhadores, coadunando-se com o surgimento da sociedade de massas.

Nesse sentido, é preciso destacar que a CRFB/1988 estabeleceu como seu fundamento a dignidade da pessoa humana e os valores sociais do trabalho e da livre iniciativa, garantiu o direito à saúde dos trabalhadores e a proteção deles no que toca à saúde, segurança e higiene, bem como fixou como princípio da ordem econômica a função social da propriedade e a defesa do meio ambiente (arts. $1^{\circ}$, III e IV, art. $3^{\circ}$, I, art. $6^{\circ}$, art. $7^{\circ}$, XXII, e art. 170 , III e VI, todos da CRFB/1988), dentre outros.

Deste modo, percebe-se que a omissão da CLT e da MP no 927/2020 não afasta a aplicação de outras normas do ordenamento jurídico brasileiro, de aplicação subsidiária, o que se conclui a partir da interpretação gramatical do art. $8^{\circ}$ da CLT. Exemplifiquem-se o capítulo V da CLT, Lei $n^{\circ} 6.938 / 1981$ e as NR de $n^{\circ}$ s 16 e 17 do então Ministério do Trabalho (atualmente Secretaria de Trabalho do Ministério da Economia), que devem ser aplicados naquilo que for compatível, atentando-se para as espeficidades do teletrabalho, considerandose que preponderantemente será desenvolvido fora do ambiente de trabalho.

Citado capítulo V da CLT trata da segurança e da medicina do trabalho, devendo suas regras ser aplicadas também no que diz respeito ao meio ambiente de trabalho do teletrabalhador, com as adaptações que se fizerem necessárias, a exemplo da edição de ordens de serviço quanto à orientação dos trabalhadores quanto às formas de execução para prevenção de acidentes de trabalho e doenças ocupacionais, cabendo, inclusive, a aplicação de penalidades por seu descumprimento (art. 157, II e art. 158, II, da CLT).

Nesse tocante, a dificuldade da fiscalização recairia no fato de o trabalhador poder realizar seu trabalho em qualquer lugar. Ocorre que isso não representaria óbice, uma vez que a fiscalização poderia ser feita presencial ou até virtualmente, mediante agendamento e ajuste entre as partes. A própria fiscalização no domicílio não seria um entrave, podendo ser aplicada, por analogia, as disposições da Lei Complementar $n^{\circ} 150 / 2015$, quando versam sobre a fiscalização no domicílio em que se verifica o trabalho doméstico, respeitando-se a inviolabilidade do domicílio (SILVA, 2017).

Já no que diz respeito à Lei $n^{\circ}$ 6.938/1981, que trata da Política Nacional do Meio Ambiente, cujos conceitos devem ser invocados também na seara laboral, aplica-se princípio do poluidor-pagador, tendo em vista que o empregador não pode poluir a saúde do trabalhador, devendo pagar para protegê-la (prevenção) e, na hipótese de causar prejuízos ao trabalhador, 
deverá ser responsabilizado, pagando pela poluição (reparação), nos termos do art. 927 do Código Civil c/c art. $8^{\circ}$ da CLT.

No que se refere ao princípio da prevenção, importa dizer que o empregador deve atuar de forma a prevenir os riscos já conhecidos quanto ao exercício do teletrabalho, enquanto que pelo princípio da precaução, cabe ao empregador prevenir os riscos mesmo que ainda não tenha certeza de sua potencialidade lesiva. Deverá, inclusive, proporcionar a informação necessária ao trabalhador, promovendo sua educação também no que diz respeito ao trabalho seguro. Tais princípios ambientais (poluidor-pagador, prevenção e precaução) também podem ser aplicados, inclusive quanto à desconexão (AMADO, 2018).

Pelo exposto, defende-se que o art. 75-E da CLT deve ser interpretado sistematicamente para compreender toda a proteção albergada pelo ordenamento jurídico brasileiro ao meio ambiente de trabalho, com as especificidades que se fizerem necessárias para cada caso concreto, aplicando-se, inclusive, os princípios ambientais do trabalho, além das normas internacionais ratificadas pelo Brasil, como a já mencionada Convenção nº 155 da OIT.

\section{Conclusões}

A pandemia do novo coronavírus catalisou o uso do teletrabalho à figura de protagonista, havendo contribuído para a quebra de diversos paradigmas, inclusive o de que o trabalhador precisaria prestar o trabalho na sede da empresa para que fosse produtivo. Desta forma, o teletrabalho vem sendo utilizado como forma de preservação das empresas e também dos postos de trabalho, devendo ser estudada de forma mais aprofundada a questão do meio ambiente de trabalho dos teletrabalhadores.

Pela pesquisa, percebeu-se que o teletrabalho é espécie de trabalho a distância, não se confundindo com o trabalho externo, tampouco com o trabalho em domicílio. Verificou-se ainda que, a despeito de a CLT e a MP 927 terem sido omissas quanto ao detalhamento do meio ambiente de trabalho, o ordenamento jurídico brasileiro deve ser analisado sistematicamente para suprir referidas lacunas, inclusive no que diz respeito às normas internacionais ratificadas pelo Brasil.

Nesse sentido, o empregador não se exime da responsabilidade pelo meio ambiente de trabalho pelo simples fato de instruir os empregados de maneira expressa e ostensiva no que se refere às precauções a tomar para evitar doenças e acidentes de trabalho.

Da mesma forma, a mera assinatura do empregado no termo de responsabilidade, comprometendo-se a cumprir as instruções de seu empregador, não é suficiente para atrair a 
responsabilidade exclusiva da vítima em caso de doença e acidente de trabalho. Faz-se, portanto, necessária a análise do contexto fático, no caso concreto, a fim de apreciar se existe responsabilidade do empregador por doença ou acidente de trabalho do teletrabalhador.

Outrossim, espera-se que os empregadores adotem medidas para não causar prejuízos à saúde do trabalhador, em obediência aos princípios jusambientais do poluidor-pagador, da prevenção e da precaução, em um viés preventivo e não repressivo, pois o que se pretende é a preservação da saúde, da higiene e da segurança do trabalhador, concretizando-se o comando constitucional.

Deste modo, tendo em vista que as doenças e os acidentes do trabalho são causados por uma multiplicidade de fatores, será indispensável a análise das diversas normas quanto ao Direito Ambiental do Trabalho, que se encontram de forma difusa no ordenamento jurídico brasileiro, para o fim de verificar se houve a sua observância.

Por fim, conclui-se que o teletrabalhador possui o direito fundamental ao meio ambiente laboral equilibrado e que é dever do empregador orientar e fiscalizar o teletrabalhador quanto ao exercício de trabalho, não apenas sobre os impactos ergonômicos, mas também saúde física, mental e emocional, respeitando-se ainda o direito à desconexão, sendo cabível a tutela preventiva e repressiva dele. Tudo isso promoverá a dignidade dos trabalhadores, sua saúde e será observada a função social da propriedade.

\section{REFERÊNCIAS}

AMADO, João Leal. Contrato de trabalho. 3. ed. Coimbra: Almedina, 2019. p. 1030-138. ISBN 978-972-40-8014-7.

AMADO, João Leal. Tempo de trabalho e tempo de vida: sobre o direito à desconexão profissional. Revista do Tribunal Regional do Trabalho da 15. Região, São Paulo, n. 52, p. 255268, jan./jun. 2018. ISSN 1679-8694.

BONAVIDES, Paulo. Curso de Direito Constitucional. 29. ed. São Paulo: Malheiros, 2014. p. 574-593. ISBN 978-85-392-0229-4.

BORGES, Theanna de Alencar. O controle de convencionalidade das Convenções da OIT como instrumento de promoção do trabalho decente. In: FARIAS, James Magno Araújo (Org.). Trabalho e humanidade: em homenagem ao centenário da OIT e aos 10 anos da escola

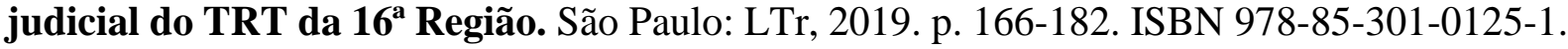


BRASIL. [Constituição (1988)]. Constituição da República Federativa do Brasil de 1988. Brasília, DF: Presidência da República. Disponível em: http://www.planalto.gov.br/ccivil_03/constituicao/ConstituicaoCompilado.htm. Acesso em: 14 jul. 2020.

BRASIL. Decreto-lei $\mathbf{n}^{0}$ 5.452, de $1^{\circ}$ de maio de 1943. Aprova a Consolidação das Leis do Trabalho. Brasília, DF: Presidência da República. Disponível em: http://www.planalto.gov.br/ccivil_03/decreto-lei/del5452compilado.htm. Acesso em: 14 jul. 2020 .

BRASIL. Lei Complementar $\mathbf{n}^{\mathbf{0}} \mathbf{1 5 0}$, de $\mathbf{1}^{\mathbf{0}}$ de junho de 2015. Dispõe sobre o contrato de trabalho doméstico; altera as Leis no 8.212, de 24 de julho de 1991, no 8.213, de 24 de julho de 1991, e no 11.196, de 21 de novembro de 2005; revoga o inciso I do art. 3o da Lei no 8.009, de 29 de março de 1990, o art. 36 da Lei no 8.213, de 24 de julho de 1991, a Lei no 5.859, de 11 de dezembro de 1972, e o inciso VII do art. 12 da Lei no 9.250, de 26 de dezembro 1995; e dá outras providências. Brasília, DF: Presidência da República. Disponível em: http://www.planalto.gov.br/ccivil_03/leis/lcp/Lcp150.htm. Acesso em: 14 jul. 2020.

BRASIL. Lei $n^{0}$ 10.406, de 10 de janeiro de 2002. Institui o Código Civil. Brasília, DF: Presidência da República. Disponível em: http://www.planalto.gov.br/ccivil_03/leis/2002/110406compilada.htm. Acesso em: 14 jul. 2020.

BRASIL. Lei $\mathbf{n}^{0}$ 13.467, de 13 de julho de 2017. Altera a Consolidação das Leis do Trabalho (CLT), aprovada pelo Decreto-Lei $n^{\circ} 5.452$, de $1^{\circ}$ de maio de 1943 , e as Leis $n^{\circ} 6.019$, de 3 de janeiro de 1974, 8.036, de 11 de maio de 1990, e 8.212, de 24 de julho de 1991, a fim de adequar a legislação às novas relações de trabalho. Brasília, DF: Presidência da República. Disponível em: http://www.planalto.gov.br/ccivil_03/_ato2015-2018/2017/lei/113467.htm. Acesso em: 14 jul. 2020.

BRASIL. Lei $\mathbf{n}^{\mathbf{0}}$ 6.938, de 31 de agosto de 1981. Dispõe sobre a Política Nacional do Meio Ambiente, seus fins e mecanismos de formulação e aplicação, e dá outras providências. Brasília, DF: Presidência da República. Disponível em: http://www.planalto.gov.br/ccivil_03/leis/L6938compilada.htm. Acesso em: 14 jul. 2020.

BRASIL. Medida Provisória $\mathbf{n}^{\circ}$ 927, de 22 de março de 2020. Dispõe sobre as medidas trabalhistas para enfrentamento do estado de calamidade pública reconhecido pelo Decreto Legislativo $\mathrm{n}^{\circ}$ 6, de 20 de março de 2020, e da emergência de saúde pública de importância internacional decorrente do coronavírus (covid-19), e dá outras providências. Brasília, DF: Presidência da República. Disponível em: http://www.planalto.gov.br/ccivil_03/_ato20192022/2020/mpv/mpv927.htm. Acesso em: 14 jul. 2020.

CASSAR, Volia Bomfim. Direito do Trabalho: de acordo com a reforma trabalhista Lei 13.467/2017. 15. . ed. rev., atual. e ampl. Rio de Janeiro: Forense; São Paulo: MÉTODO, 2018. p. 668-670. ISBN 978-85-309-7885-3. 
DELGADO, Mauricio Godinho; DELGADO, Gabriela Neves. A reforma trabalhista no Brasil: com os comentários à Lei n. 13.467/2017. São Paulo: LTr, 2017. p. 135-140. ISBN 97885.361-9399-1.

ILO. Convenio $\mathbf{n}^{\mathbf{0}} \mathbf{1 7 7}$ sobre el trabajo a domicilio. Disponível em: https://www.ilo.org/dyn/normlex/es/f?p=NORMLEXPUB:12100:0::NO::P12100_INSTRUM ENT_ID:312322. Acesso em: 14 julho 2020.

MAZZUOLI, Valerio de Oliveira. Controle jurisdicional de convencionalidade das leis [Kindle Edition]. 5. ${ }^{\text {. }}$ ed. Rio de Janeiro: Forense, 2018. ISBN 978-85-309-8190-7.

MIRANDA, Jorge. Direitos Fundamentais. 2. ed. Coimbra: Almedina, 2018. p. 79-153. ISBN 978-972-40-7217-3.

OIT. Convenção $\mathbf{n}^{\mathbf{0}}$ 155. Segurança e saúde dos Trabalhadores. Disponível em: https://www.ilo.org/brasilia/convencoes/WCMS_236163/lang--pt/index.htm. Acesso em: 14 jul. 2020.

SILVA, Homero Batista Mateus da. Comentários à reforma trabalhista. 2. ${ }^{\text {a }}$ ed. rev. e atual. São Paulo: Revista dos Tribunais, 2017. p. 27-39. ISBN 978-85.203-6872-5.

SILVA, Homero Batista Mateus da. Legislação trabalhista em tempos de pandemia: comentários às Medidas Provisórias 927 e 936. São Paulo: Thomson Reuters Brasil, 2020. p. 55-60. ISBN 978-65.5614-027-8. 